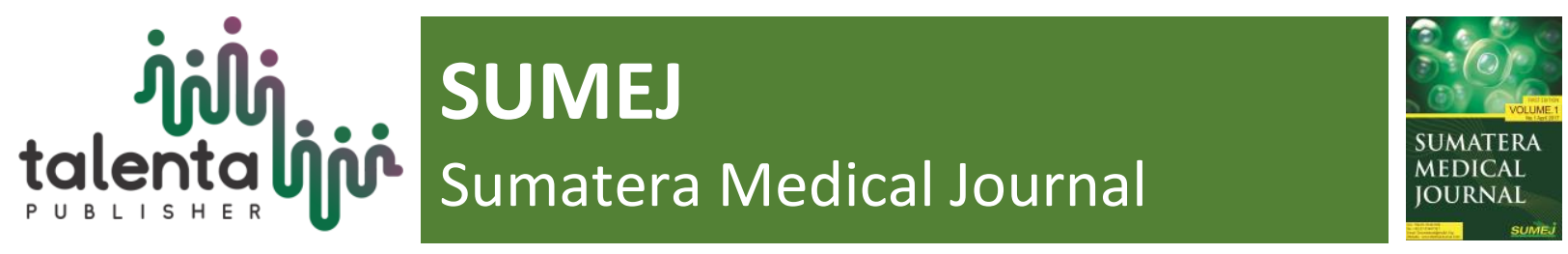

\title{
PROFILE OF SINONASAL TUMOR PATIENTS IN ADAM MALIK GENERAL HOSPITAL MEDAN 2016-2018
}

\author{
Ulfatul Ulya ${ }^{1}$, Ashri Yudhistira ${ }^{2}$, Andrina Y.M Rambe ${ }^{3}$, Yetty Machrina ${ }^{4}$ \\ ${ }^{1}$ Faculty of Medicine, Universitas Sumatera Utara, Medan, North Sumatera, Indonesia \\ ${ }^{2}$ Department of Otorhinolaryngology Head and Neck Surgery, Faculty of Medicine, Universitas Sumatera \\ Utara, Medan, North Sumatera, Indonesia \\ ${ }^{3}$ Department of Otorhinolaryngology Head and Neck Surgery, Faculty of Medicine, Universitas Sumatera \\ Utara, Medan, North Sumatera, Indonesia \\ ${ }^{4}$ Department of Physiology, Faculty of Medicine, Universitas Sumatera Utara, Medan, North Sumatera, \\ Indonesia
}

\begin{abstract}
Sinonasal tumor is a neoplasm that arises from nasal and paranasal sinus tissue. It is rarely found, only $<3 \%$ of all malignancy in head and neck, and $1 \%$ of all malignancy in the body. Although it is rarely found, it can cause serious complication in adult. Unspecific sign and symptoms of sinonasal tumor often make the patients ignore the disease. It leads to the diagnosis of this disease becomes late and the patients come to the doctor in advanced stage. This research was conducted to know about the profile of sinonasal tumor patients in H. Adam Malik Medan Hospital on 2016-2018. The study was a descriptive study with retrospective approach. The data used are secondary data taken from medical records. The data were analyzed using a statistical application programs. Sinonasal tumor patients in RSUP HAM Medan are 158 patients, where 95 patients met the inclusion criteria, consisting of 24 benign tumors $(25,3 \%)$ and 71 malignant tumors $(74,7 \%)$. The majority of patients are male $(71,6 \%)$, and the highest age group in in 51-60 years old (31,6\%). The main complaints felt by the patients were nasal symptoms (64,2\%), the location of tumors mostly found in nasal cavity (50,5\%), the most histopathological type is NKSCC (43,2\%), the most occupation is self-employment (26\%), and the treatment of the patients are surgery $(29,5 \%)$.
\end{abstract}

Keyword: Sinonasal Tumor, Profile, Sinonasal Cancer

Received date month year. | Revised date month year | Accepted date month year

\section{Introduction}

Nasal and paranasal sinus tumors are rare tumors, which are only <3\% of head and neck malignancies and about $1 \%$ of whole body malignancies [1]. Although rarely found, these tumors can cause serious complications in adults. There are several factors that make diagnosis of this tumor difficult, including the type of histopathology, anatomical access that is difficult to find, and clinical symptoms that are not so typical. The most commonly reported symptoms at the time

*Corresponding author at: Faculty of Medicine, Universitas Sumatera Utara, Medan, North Sumatera, Indonesia

E-mail address: ulfatlya@gmail.com 
of diagnosis are nasal obstruction, diplopia, facial swelling, epistaxis, proptosis, headache, nasal mass, and hearing loss [2].

The sinonasal benign tumors are relatively common with an overall incidences of 3-5. However, most of these tumors do not cause symptoms so often found accidentally on imaging examination or nasal endoscopy. The most common type of benign sinonasal tumor is sinonasal inverted papilloma [3]. According to Hennessey and Reh (2013), inverted papilloma occurs at a rate of $0.2-6$ cases per 100,000 patients per year and represent $0.5-4 \%$ sinonasal tumors with a male and female ratio of 3: 1 . The age most affected is between the fifth and sixth decades of life [4].

While sinonasal malignancies are rare cases with an incidence rate of around 0.55 cases per 100,000 population per year [5]. The highest incidence of sinonasal malignancy is found in Japan, which is 2 cases per 10,000 population per year [6]. In Europe, in 2003 around 14,500 people were diagnosed with epithelial tumors originating from the nasal cavity [7]. Squamos Cell Carcinoma (SCC) is the most common form, which is around $65-70 \%$ in all sinonasal malignancies [8].

The tumors stage, histopathological type, and lymph node involvement are prognostic factors of this disease. Most sinonasal malignant tumors require surgery to remove cancerous tissue. Because of its proximity to vital structures such as brain, optic nerve and internal carotid arteries, this surgery can cause significant morbidity in patients [9]. Sinonasal malignancy has a poor prognosis. Mortality and relapse can occur in patients after receiving treatment. The signs and symptoms that are not so typical of sinonasal malignancies often make patients ignore these symptoms. This cause the diagnosis of the disease being late so patients often come in an advanced stage [10].

\section{Method}

This study method is descriptive with retrospective approach. Samples were taken by total sampling method. This study involved 158 cases of sinonasal tumor patients in RSUP H. Adam Malik Medan in 2016 - 2018. The data used are secondary data taken from medical records. When collecting data, the researcher made sure the medical record was complete and the diagnosed tumor was sinonasal primary tumor. Of 158 cases, only 95 medical records met the requirements to be included in this study. Variables which are tested in this study were age, sex, occupation, main symptoms, location of tumors, type of tumors, histological type of tumors, and management of tumors. All data were analyzed with statistical application programs and presented in frequency table. 


\section{Result}

Table 1. Samples Characteristic

\begin{tabular}{|c|c|c|c|}
\hline Variable & Category & Frequency & Percentage (\%) \\
\hline \multirow[t]{6}{*}{ Age } & $<20$ & 5 & 5,3 \\
\hline & $20-30$ & 7 & 7,4 \\
\hline & $31-40$ & 17 & 17,9 \\
\hline & $41-50$ & 15 & 15,8 \\
\hline & $51-60$ & 30 & 31,6 \\
\hline & $>60$ & 21 & 22,1 \\
\hline \multirow[t]{2}{*}{ Sex } & Male & 68 & 71,6 \\
\hline & Female & 27 & 28,4 \\
\hline \multirow[t]{10}{*}{ Occupation } & Civil Servant & 4 & 4,2 \\
\hline & Private Employee & 8 & 8,4 \\
\hline & Farmer & 24 & 25,3 \\
\hline & Fisherman & 3 & 3,2 \\
\hline & Driver & 2 & 2,1 \\
\hline & Self-employed & 25 & 26,3 \\
\hline & Handyman & 1 & 1,1 \\
\hline & Housewife & 17 & 17,9 \\
\hline & Student & 5 & 5,3 \\
\hline & Unemployed & 6 & 6,3 \\
\hline \multirow[t]{5}{*}{ Main Symptom } & Nasal Symptom & 61 & 64,2 \\
\hline & Facial Symptom & 17 & 17,9 \\
\hline & Oral Symptom & 3 & 3,2 \\
\hline & Orbital Symptom & 10 & 10,5 \\
\hline & $\begin{array}{l}\text { Intracranial } \\
\text { Symptom }\end{array}$ & 4 & 4,2 \\
\hline \multirow[t]{3}{*}{ Tumor Location } & Nasal Cavity & 48 & 50,5 \\
\hline & Paranasal Sinus & 18 & 18,9 \\
\hline & $\begin{array}{l}\text { Nasal Cavity and } \\
\text { Paranasal Sinus }\end{array}$ & 29 & 30,5 \\
\hline \multirow[t]{2}{*}{ Tumor Type } & Benign & 24 & 25,3 \\
\hline & Malignant & 71 & 74,7 \\
\hline \multicolumn{2}{|c|}{ Total } & 95 & 100 \\
\hline
\end{tabular}


Table 1 shows the characteristic of all samples in this study. Most of the samples were in $51-60$ age category $(31,6 \%)$, where the most patients are men $(71,6 \%)$. The most common symptoms are nasal symptoms $(64,2 \%)$ and the location of tumors are mostly found in nasal cavity $(50,5 \%)$.

Table 2. Tumor Histologic Type

\begin{tabular}{lcc}
\hline Histologic Type & Frequency & Percentage (\%) \\
\hline Benign Tumors & 2 & 2,1 \\
Neurofibroma & 1 & 1,1 \\
Meningothelial & & \\
Meningioma & 3 & 3,2 \\
Inverted Papilloma & 1 & 1,1 \\
Midline Granuloma & & \\
Sinonasal & 12 & 12,6 \\
Benign Polyp & 1 & 1,1 \\
Benign Cyst & 1 & 1,1 \\
Adenomatous Polyp & 1 & 1,1 \\
Ossifying Fibroma & 2 & 2,1 \\
Fibrous Dysplasia & & \\
Malignant Tumors & & 100 \\
Adenocarcinoma & 65 & 6,3 \\
Adenoid Cystic & 6 & 4,2 \\
Carcinoma & 4 & 10,5 \\
KSCC & 10 & 43,2 \\
NKSCC & 41 & 2,1 \\
Fibrosarcoma & & \\
Melanoma Malignant & & \\
Undifferentiated & & \\
Carcinoma & & \\
Sinonasal Non- & & \\
Intestinal type & & \\
Adenocarcinoma low & & \\
grade & & \\
\hline \multicolumn{1}{c}{ Total } & & \\
\hline
\end{tabular}

As shown in table 2, the tumors are divided into benign and malignant tumors. The most common benign tumors found are benign polyp $(12,6 \%)$, while the malignant tumors are non-keratinizing squamous cell carcinoma $(43,2 \%)$. 
Table 3. Tumor Management

\begin{tabular}{lcc}
\hline \multicolumn{1}{c}{ Therapy } & Frequency & Percentage (\%) \\
\hline Surgery & 28 & 29,5 \\
Chemotherapy & 15 & 15,8 \\
Radiation & 4 & 4,2 \\
Surgery and Chemotherapy & 15 & 15,8 \\
Surgery and Radiation & 5 & 5,3 \\
Chemoradiation & 9 & 9,5 \\
Surgery and Chemoradiation & 19 & 20 \\
\hline \multicolumn{1}{c}{ Total } & 95 & 100 \\
\hline
\end{tabular}

Table 2 shows the most therapy given to the patients is surgery.

\section{Discussion}

Based on the results of this study, it was found that sinonasal tumors were very common in the age range of $51-60$ years as many as 30 people (31.6\%). The mean age (mean) in this study was 47.9 years (range $=7-72$, mode $=55$ years). This is consistent with the literature which says that the incidence of sinonasal tumors frequently occurs in the 5th decade of life [11]. In a similar study conducted by Krisnarendra [12] regarding the characteristics of sinonasal cancer sufferers in RSUP Sanglah during January-December 2014 period, the highest age group of sinonasal cancer patients was in the age range of 51 - 60 years by $28 \%$, and the lowest age was under the age of 20 year which is as much as $4 \%$.

Sinonasal tumor incidences are more common in men than women. This might be due to occupational factors and carcinogenic exposure. In this study, sinonasal tumor mostly found in men $(71,6 \%)$ than women $(28,4 \%)$. According to Mensi et al., [13] from the results of research conducted to look at the incidence of sinonasal cancer with occupational exposure, men are more exposed to carcinogenic substances, as much as $49.3 \%$ and women as much as $16.7 \%$. The most common exposure to men is wood dust and leather dust. In addition, smoking history also has a major influence on the incidence of sinonasal tumors.

The frequency, anatomical location and histological type of sinonasal tumors vary greatly across geographical region due to several factors such as, history of chronic sinusitis, use of drugs in the nose, smoking and occupation that strongly exposed to wood, dust skin and nickel compound. Some other agents suspected of causing this tumor are hexavalent chromium compound, welding fumes, arsenic, mineral oil, organic solvent, and textile dust [13]. From the results of this study, incidences of sinonasal tumor based on occupation was found the most self-employment with 25 patients $(26.3 \%)$, followed by farmers as many as 24 patients $(25.3 \%)$. Because of the selfemployed sector is very broad, unfortunately that the status of these self-employment jobs cannot 
be given a very typical picture of the patient's field or sector of work itself. According to Youlden et al., [14] the main work that has been identified as a risk factor for the occurrence of this sinonasal tumor are forest workers, carpenters, furniture makers and paper industry workers. In research conducted by Shavilla et al., [15] regarding the prevalence of sinonasal cancer in the THT-KL Polyclinic RS. Hasan Sadikin Bandung, January 2013-2015, it was recorded that as many as 67 patients (36.4\%) were farmers and 63 patients (34.2\%) were laborers.

Most types of tumors in this study were malignant tumors with total of 71 patients (74.7\%), while benign tumors were 24 patients (25.3\%). Most of the patients complained symptoms in the nose, which was 61 patients $(64,2 \%)$. In addition, the largest sinonasal frequency occurs at an average of age 51 years. Therefore, it is crucial for doctors to evaluate patients adults with these symptoms. Of 71 malignant tumors found in this study, the most histopathological type was nonkeratinizing squamous cell carcinoma in 41 patients (43.2\%). The same thing is also found in research conducted by Fadly et al., [16] at RSUP H. Adam Malik regarding profiles sinonasal cancer patients in 2010-2015, the most sinonasal malignant tumors found were NKSCC with 53 patients $(47.3 \%)$. As for benign tumors the most found by histopathological type was benign polyp 12 patients (12.6\%). According to Maheshwari and Bansal [17] benign polyp is a mass caused by chronic inflammation of the sinonasal mucosa and this type of tumor is most often found. The pathogenesis of this tumor is not yet known with certainty, but in previous studies found that this tumor very closely related to allergies, infections, asthma, and sensitivity to aspirin patients $(64,2 \%)$.

Sinonasal tumor patients generally receive therapy in the form of surgery, as many as 28 patients (29.5\%). In addition, some patients also receive therapy adjuvant in the form of chemotherapy and radiation, or a combination of the two after surgery. From the results of this study, we found the patients who received chemotherapy as many as 15 patients $(15.8 \%)$, radiation as many as 4 patients $(4.2 \%)$, surgery and chemotherapy for 15 patients $(15.8 \%)$, surgery and radiation for 5 patients $(5.3 \%)$, chemoradiation for 9 patients $(9.5 \%)$, and surgery and chemoradiation for 19 patients (20\%). According to Youlden et al., [18] surgery is still the main option for sinonasal tumor therapy where resection of small tumors can provide such a good prognosis. However, almost all sinonasal tumors are detected at an advanced stage due to late diagnosis. This makes surgery difficult. Post-operative radiotherapy is generally done, but the prognosis is not too significant.

\section{Conclusion}

The most sinonasal tumor patients in RSUP HAM are male with a range of 51 - 60 years of age, the main complaint is nasal symptoms, the location of most tumors are in nasal cavity, the most tumor type is NKSCC, and the most common therapy given is surgery. 


\section{REFERENCES}

[1] Turner, J.H \& D.Reh, D, 2011, Incidence and Survival in Patients with Sinonasal Cancer: A Historical Analysis of Population-Based Data. Wiley online library, 55(June), pp. 1-28. doi: 10.1002/hed.

[2] Danesh-Sani, S.A, Sarafraz, A, Chamani, M \& Derakhshandeh, H., 2016, Paranasal Sinuses Malignancies: A 12-year review of clinical characteristics, Med Oral Patol Oral Cir Bucal., 21(5), pp. e626-e630. doi: 10.4317/medoral.21170.

[3] Weizman, N, Leider-Trejo, L, Fliss, M \& Gil, Z., 2012, Tumours of the skull base and paranasal sinuses. New Delhi: Springer (India) Pvt. Ltd. pp.19

[4] Hennessey, P. T. \& Reh, D. D., 2013, "Benign sinonasal neoplasms," Am J Rhinol Allergy, 27(SUPPL.1), pp. 31-34. doi: 10.2500/ajra.2013.27.3893.

[5] Glicksman, J. T. et al., 2018, "Sinonasal quality of life after endoscopic resection of malignant sinonasal and skull base tumors," Laryngoscope, 128(4), pp. 789-793. doi: 10.1002/lary.26833.

[6] Fadly, F., Farhat \& Asnir, R. A., 2018, "Profile of sinonasal malignant tumor patients in Adam Malik General Hospital Medan-Indonesia," Bali Med J, 7(1), pp. 137-140. doi: 10.15562/bmj.v7i1.810.

[7] Van Dijk, B.A.C, Gatta, G, Capocaccia, R, Pierranunzio, Strojan, P \& Licitra, L., 2012, "Rare cancers of the head and neck area in Europe," European Journal of Cancer. Elsevier Ltd, 48, pp. 783-796. doi: 10.1016/j.ejca.2011.08.021.

[8] Stelow, E.B \& Bishop, J.A., 2017, "Update from the 4th Edition of the World Health Organization Classification of Head and Neck Tumours: Tumors of the Nasal Cavity, Paranasal Sinuses and Skull Base," Head and Neck Pathology. Springer US, 11(1), hal. 3-15. doi: 10.1007/s12105-017-0791-4.

[9] Cengiz, A.B, Uyar, M, Comert, E, Dursun, E \& Eryilmaz, A., 2013, "Sinonasal Tract Malignancies: Prognostic Factors and Surgery Outcomes," Iran Red Cres Med J., 15(12). doi: 10.5812/ircmj.14118.

[10] Poursadegh, M, Poursadegh, F, Esmaeili, M \& Bakhshaee, M., 2015, "Epidemiological survey of sinonasal malignancy in North-East Iran," Iranian Journal of Otorhinolaryngology, 27(80), pp. 225-229.

[11] Hennessey, P. T. \& Reh, D. D., 2013, "Benign sinonasal neoplasms," Am J Rhinol Allergy, 27(SUPPL.1), pp. 31-34. doi: 10.2500/ajra.2013.27.3893.

[12] Krisnarendra \& Saputra, A.D, 2018, "Karakteristik Pada Penderita Kanker Sinonasal di RSUP Sanglah Periode Januari - Desember 2014", E-Jurnal Medika, 7(8).

[13] Mensi, C, Consoni, D, Sieno, C, Matteis, S.D, Riboldi, L \& Bertazzi, P.A., 2013, "Sinonasal Cancer and Occupational Exposure in a Population-Based Registry," Int J Otolaryngol, 2013, pp. 1-7. doi: 10.1155/2013/672621.

[14] Youlden, D.R, Cramb, S.M, Peters, S, Porceddu, S.V, Moller, H, Fritschi, L, Baade, P.D., 2013, International comparisons of the incidence and mortality of sinonasal cancer. Cancer Epidemiology, 37(6), pp.770-779.

[15] Shavilla, E, Aroeman, N.A, Dewi, Y.A \& Permana, A.D., 2016, "Prevalensi Kanker Sinonasal di Poliklinik THT-KL RS. Hasan Sadikin Bandung, Januari 2013 - Juli 2015" Tunas Med Jurnal, 3(1).

[16] Fadly, F., Farhat \& Asnir, R. A., 2018, "Profile of sinonasal malignant tumor patients in Adam Malik General Hospital Medan-Indonesia," Bali Med J, 7(1), pp. 137-140. doi: 10.15562/bmj.v7i1.810.

[17] Maheshwari, A. and Bansal, A., 2017, Clinico-pathological spectrum of sinonasal masses: a tertiary care hospital experience. International Journal of Otorhinolaryngology and Head and Neck Surgery, 3(4), p.1015. 
[18] Youlden, D.R, Cramb, S.M, Peters, S, Porceddu, S.V, Moller, H, Fritschi, L, Baade, P.D., 2013, International comparisons of the incidence and mortality of sinonasal cancer. Cancer Epidemiology, 37(6), pp.770-779. 